\title{
A POSSÍVEL JUSTIFICAÇÃO RACIONAL DA MORAL E O PAPEL DA ARGUMENTAÇÃO PRÁTICA NA TIPIFICAÇÃO E PUNIÇÃO DE CONDUTAS CONTRÁRIAS Ấ MORALIDADE COMETIDAS POR SERVIDORES PÚBLICOS ${ }^{1}$
}

\author{
Luiz Egon Richter \\ Universidade de Santa Cruz do Sul - UNISC - Brasil \\ Augusto Carlos de Menezes Beber \\ Universidade de Santa Cruz do Sul - UNISC - Brasil
}

Resumo

O presente artigo tem como escopo um breve estudo sobre a aplicação do direito no constitucionalismo discursivo e de que forma são identificadas pelo Poder Público as condutas atentatórias à moralidade praticadas por servidores. Para tanto, pretende-se adotar as premissas da teoria da argumentação jurídica, especialmente aquelas adotadas por Alexy em sua teoria do discurso prático racional geral. Primeiramente, far-se-á uma breve retrospectiva, indagando-se sobre a relação da moral no conceito de direito. Em seguida, procurar-se-á saber como se realiza a justificação dos discursos práticos a partir das regras da argumentação, para, por fim, realizar uma análise exemplificativa da legislação e de decisões jurídicas que incidiram em punições a servidores públicos que realizaram atos atentatórios à moralidade. Com isso, quer-se trazer luz ao debate da ética no serviço público, realçando a necessidade de um conceito de direito complexo e de uma prática discursiva sofisticada.

Palavras-chave: Argumentação. Ética Pública. Direito. Moral. Servidores públicos.

\section{Introdução}

Segundo relatório divulgado pela Controladoria-Geral da União (2015), somente no ano de 2014 o Poder Público federal aplicou 550 expulsões punitivas a servidores públicos por atos contrários ao Regime Jurídico Único do Servidor Público Federal, instituído pela Lei $\mathrm{n}^{\circ} 8112 / 90 .^{2}$ Cerca de $67,17 \%$ das punições teve como causa atos relacionados com a corrupção, figurando em seguida abandono de cargo, inassiduidade ou acumulação ilícita de cargos, com 22,43\%, agir de forma desidiosa, com 2,89\%, e a participação em gerência ou administração de sociedade privada, com 1,05\%.

\footnotetext{
${ }^{1}$ Este artigo é fruto dos debates realizados no bojo do Projeto interinstitucional de redes de grupos de pesquisa sobre o tema patologias corruptivas nas relações entre Estado, Administração Pública e sociedade: causas, consequências e tratamentos, vinculado ao CNPq, referente ao eixo "Responsabilidade Administrativa por atos de Corrupção no âmbito da Contratação Pública".

${ }^{2}$ Contabilizam-se como punições expulsivas: demissão e cassação de aposentadoria.
} 
Muitas, senão quase todas as penalidades expulsivas impostas aos servidores são referentes não somente a comportamentos antijurídicos, mas também a comportamentos socialmente imorais. Não obstante suas figuras normativas estarem positivadas no referido Estatuto dos Servidores, sua prática lesiva está sempre vinculada a uma violação do princípio constitucional da moralidade. Este, por sua vez, possui alcance muito maior do que as espécies normativas positivadas sancionadoras de condutas, seja por sua natureza normativa diferenciada, seja por seu status constitucional. Entretanto, a amplitude da força normativa da moralidade como princípio possui limitações da própria linguagem da moral, localizada entre a axiologia e a deontologia.

O ordenamento jurídico positivo apresenta como um todo expressões de juízos valorativos, os quais não são preenchidos pela letra da legislação positiva. A Lei de Introdução às Normas do Direito Brasileiro assim determina: “As leis, atos e sentenças de outro país, bem como quaisquer declarações de vontade, não terão eficácia no Brasil, quando ofenderem a soberania nacional, a ordem pública e os bons costumes" (BRASIL, 1942). Mas o que são os bons costumes de que fala a lei? Da mesma forma, rege o art. 1735, V, do Código Civil: "Não podem ser tutores e serão exonerados da tutela, caso a exerçam: V - as pessoas de mau procedimento, ou falhas em probidade, e as culpadas de abuso em tutorias anteriores" (BRASIL, 2002). Mas quem é o sujeito de mau procedimento, ou, mais especificamente, que tipo de ação cometida é hábil para qualificar um procedimento como mau?

A partir do exposto, pergunta-se: que espécie de ação ou omissão o servidor público deve cometer para ser o ato reconhecido como inassíduo, desidioso, imoral ou contra a ordem pública? A inicial indeterminação dos conteúdos jurídicos delega ao poder público a tarefa de esclarecer que espécie de ação o direito coíbe, tarefa que, no Estado de Direito, realiza-se por meio de uma construção argumentativa. Compreender como se dá essa construção, portanto, é o ponto de partida para compreender como são identificadas as condutas incompatíveis com o serviço público a fim de produzir uma melhor gestão da coisa pública.

Contudo, se, pelo o que aparenta, para se fazer cumprir um mandamento jurídico necessita-se de um julgamento sobre convicções morais - ou seja, que defina o que é correto, devido - deve-se antes buscar entender qual é o espaço de uma argumentação moral no campo do direito e qual é a sua relação com um sistema de normas qualificado como jurídico. Para tanto, é necessário confrontar duas teses, uma que segrega o direito da moral e outra que os unifica, que assim permita considerar qual é o paradigma mais adaptado ao contexto do 
constitucionalismo contemporâneo. A posição aqui defendida é que, para se poder concretizar um sistema de ambições democráticas, deve-se ter em mente um conceito de direito que abarque minimamente três elementos: legalidade conforme o ordenamento, eficácia social e pretensão à correção. Assim, realizando um diálogo com o positivismo jurídico, deve-se produzir um consenso sobre qual é a relação que existe entre o direito e a moral - e que moral é esta que se relaciona com o direito.

Considerando-se a existência de uma relação conceitualmente necessária entre direito e moral, deve-se, por consequência, compreender como e se a moral pode ser racionalmente justificada em termos de direito. Utiliza-se, para tanto, da teoria do discurso prático racional geral de Alexy, assim como de seus interlocutores, que tanto contribuíram para o pensamento do autor. A teoria argumentativa servirá como base para compreender de que maneira o direito é aplicado a partir da matriz discursiva, e porque o procedimento é a forma pela qual a aplicação do direito se perfectibiliza racionalmente.

Apresentadas as referências teóricas, torna-se possível realizar uma breve análise exemplificativa da lei e da jurisprudência, com o intuito de compreender como são formados os discursos que, por exemplo, tipificam um ato como imoral que, por consequência, geram sanções ao servidor público, dependendo do regime de responsabilidade.

\section{0 problema da relação entre direito e moral através do debate entre positivismo jurídico e jusnaturalismo}

O objetivo deste capítulo é realizar uma sucinta reflexão sobre o conceito de direito e sua relação com a moral. Para isso, utilizar-se-á da mão-de-obra de diversos autores, célebres doutrinadores de Teoria do Direito que muito contribuíram para este debate. Os limites desta exposição, entretanto, permitem apenas uma ilustração compacta desta questão secular. Portanto, apesar de breve, tentar-se-á defender o posicionamento aqui adotado da forma mais clara possível, sem produzir largos prejuízos às contribuições dos autores mencionados.

A relação entre o direito e a moral sempre foi pautada pelo incansável debate entre duas teses diametralmente opostas: a tese da separação e a tese da vinculação. A tese da separação é defendida por teorias positivistas do direito, que visam, antes de tudo, a negação da metafísica e do direito natural. Teorias jusnaturalistas do direito, portanto, aproximam-se 
da defesa de uma tese da vinculação (ALEXY, 2009). ${ }^{3}$ Ambas as teorias, entretanto, partilham o mesmo problema: encontrar um critério de juridicidade para o direito, ou seja, uma forma de poder-se identificar quando se está diante de um mandamento jurídico e quando se está diante de um mandamento moral.

Pode-se dizer que o jusnaturalismo (ou jusracionalismo) desenvolveu-se como teoria predominante entre o Estado Absolutista e o Estado de Direito. A partir do desenvolvimento das atividades mercantis, a burguesia, classe em ascensão entre os séculos XVIII e XIX, buscou a negação do direito divino e o afastamento da concentração do poder nas mãos do monarca, justificando as práticas políticas e jurídicas na racionalidade humana (PACHUKANIS, 1988). ${ }^{4}$ Entretanto, a passagem do tempo mostrou o contragosto da crença em normas de caráter universal e estabelecidas aprioristicamente, fazendo o jusnaturalismo ceder lugar às codificações e para as diversas correntes positivistas que vinham surgindo por toda a Europa.

Entre as teorias positivistas que existem, a mais famosa delas, ou talvez a mais conhecida no cenário científico brasileiro, é sem dúvida a teoria de Hans Kelsen. Entre diversos mitos jurídicos, a teoria da Escola Normativista de Kelsen muito contribuiu para a formação do pensamento jurídico tal qual ele é visto e ensinado hoje, seja com seus conceitos, seja com seu olhar técnico sobre o fenômeno jurídico.

De fato, Kelsen trouxe diversos pontos que são irrenunciáveis para a compreensão da relação entre direito e moral. Sua teoria, altamente criticada, entretanto, merece uma observação mais criteriosa do que aquela realizada corriqueiramente. Kelsen não criou uma teoria do direito puro, mas uma teoria pura do direito. A pretensão do grande mestre de Viena foi criar uma teoria descritiva e universal para o direito positivo, objeto próprio de uma ciência do direito. Mesmo Kelsen admitiu o evidente - o direito está submetido às influências dos tecidos em que está inserido, como a moral e a política. A partir disso surgiu a sua mais ferrenha tese: a necessária separação conceitual entre direito e moral. Para Kelsen (2013), o indivíduo que busca saber se uma norma é direito ou não deve estar atento a um critério de validade estabelecido pelo sistema, e não se a dita norma está vigente conforme a moral.

\footnotetext{
${ }^{3}$ Note-se que Alexy não utiliza o termo jusnaturalismo como corrente oposta ao positivismo jurídico, referindose apenas como conceitos positivistas e não-positivistas.

${ }^{4}$ Ainda segundo Pachukanis, "A escola do direito natural não foi apenas a expressão mais saliente da ideologia burguesa, numa época em que a burguesia surgiu como classe revolucionária e formulou suas reivindicações de maneira aberta e coerente, mas deixou-nos também o mais profundo e claro modelo para a compreensão da forma jurídica" (PACHUKANIS, 1988, p. 33).
} 
Kelsen (2013) entendia a moral como irracional, portanto, inservível como critério de juridicidade. Se o conteúdo do que é bom, mau, justo e injusto é vazio de sentido a priori, seria, portanto, impossível determinar o que seria uma moral correta. Concordando-se com Kelsen, torna-se dedutível o fato de que o direito, na forma de instrumento de poder, não pode ser reconhecido por critérios morais variáveis, principalmente se visa ser universal e aplicado de forma equânime.

Há de se concordar em parte com a proposta kelsiana. Se existem muitos problemas ao se afirmar que o direito não corresponde a moral, também existem tantos outros ao se afirmar o oposto. A tese de Kelsen, além de atrativa, é muito útil para a prática jurídica, eis que nem sempre direito e moral caminham ao mesmo compasso. Eis o seguinte exemplo: o Tribunal de Justiça do Rio Grande do Sul absolveu, em sede de ação penal, prefeito que, além de punir um servidor público, adversário político, por ato não ofensivo à legislação trabalhista, também determinou ao mesmo horário de trabalho diferenciado dos demais. A $4^{\text {a }}$ Câmara Criminal entendeu que, embora imoral e irregular, o ato praticado não chegou a tipificar plenamente o crime de prevaricação (BRASIL, 2004). Se direito e moral pertencessem ao mesmo núcleo, o julgador, assim que identificasse a imoralidade, também identificaria o direito, o que de fato não ocorreu. Entretanto, não por isso essa classificação deixa de ser problemática.

No que consiste, então, a relação jusmoralista? Kelsen, no prólogo da segunda edição de sua Teoria Pura reconhece que, após o fim da Segunda Guerra Mundial, correntes jusnaturalistas ganharam novo fôlego no debate jurídico. As ações cometidas pelo Reich induziram os juristas a ser perguntar mais uma vez se o direito não possuiria um conteúdo valorativo, ou até que ponto uma norma injusta poderia ser considerada direito. A partir de então eclodiram diversas teorias sobre o conteúdo ético do direito, alimentando diversas críticas ao positivismo jurídico.

A problemática sobre o conteúdo valorativo do direito foi se acentuando progressivamente na medida em que complexos casos jurídicos foram surgindo e sendo debatidos no cenário mundial. O positivismo, de fato, não foi concebido originalmente como teoria da decisão do direito, mas como teoria (descritiva) do direito. Em diversos casos limítrofes, o sistema não oferecia uma resposta, o que obrigou os teóricos positivistas a buscar soluções em um campo extrajurídico. Em outros casos, a resposta oferecida pelo sistema não era almejada ou esperada em termos de direito, o que fomentou ainda mais a necessidade da revisão da relação jusmoralista. 
Em Levando os direitos a sério, Dworkin (2002) reapresentou o clássico e polêmico caso Riggs vs. Palmer, de larga utilidade para ilustrar o conflito jusmoralista. Com o intuito de desfrutar antecipadamente dos bens adjudicados por testamento, o jovem Elmer envenenou o seu avô, reivindicando para si a parte que lhe cabia da herança. Não havia restrição ao legatário no Direito das Sucessões estadunidense que o impedisse de receber o seu quinhão na hipótese de assassinato do testador. Em verdade, o direito positivo oferecia uma resposta, ainda que moralmente indesejada. Surpreendentemente, a Corte americana rejeitou a pretensão de Elmer, com base no direito suprapositivo, adotando o princípio de que ninguém pode extrair vantagens do seu comportamento ilícito.

O Tribunal Constitucional Federal alemão chegou a conclusão semelhante em decisão inédita sobre cidadania, proferida em 1968. O $11^{\circ}$ Decreto da Lei de Cidadania do Reich, por motivos racistas, determinava a perda da nacionalidade alemã aos judeus emigrados. A tarefa do Tribunal no caso era decidir se um judeu que havia emigrado para Amsterdam pouco antes da eclosão da Segunda Guerra Mundial havia perdido a cidadania alemã em função da referida norma. $\mathrm{O}$ Tribunal concluiu que não. Em sua fundamentação, destacou que o $11^{\circ}$ Decreto da Lei de Cidadania do Reich era nulo ab initio, não estando o direito e a justiça à disposição do legislador, uma vez que dispositivos legais, tais como aqueles proferidos durante o regime nacional-socialista na Alemanha, que contrariam de forma expressa princípios fundamentais da justiça, não podem ser aplicados como direito (ALEXY, 2009).

Ambas as decisões são instigantes. Em ambas as experiências, norte-americana e alemã, havia uma resposta oferecida pelo sistema de direito positivo: a concessão da herança e a perda da cidadania. Entretanto, as possibilidades jurídicas colidiram com pretensões suprapositivas que se sobressaíram. Por conseguinte, diante de um sistema complexo, que admite atos jurídicos na forma das decisões proferidas, soa inviável um conceito de direito que abarque somente os elementos legalidade conforme o ordenamento e eficácia social. Entretanto, a tese que reduz o direito a critérios morais tampouco é útil para explicar o fenômeno jurídico, pois nem toda norma injusta ou imoral deixa de ser considerada direito. A resposta que parece ser mais adequada para essa questão tem raiz em Radbruch, que, com o argumento da injustiça, entende que o direito positivo tem prioridade sobre o direito natural, mesmo quando injusto. Somente em casos de injustiça extrema, onde haja uma contradição insustentável entre o direito positivo e a justiça que esta poderá prevalecer àquele (ALEXY, 2009). 
A partir disso, é possível considerar que existem boas razões para adotar uma tese que considere uma vinculação do direito a moral, sem, contudo, excluir a relativa autonomia entre as duas esferas. Adotando-se a perspectiva de Alexy, parece correto afirmar que existe uma conexão necessária entre direito e moral. Entretanto, seguindo-se a fórmula de Radbruch, a conexão existente será qualificadora, e não classificadora. Apesar de ser uma questão altamente complexa, as razões expostas levam a crer que, ainda que haja uma conexão necessária entre o direito e a moral, essa conexão não encerra a ideia de unidade, havendo o direito e a moral núcleos próprios, entretanto, interdependentes. Assim, o direito não é em relação a moral, mas qualifica-se conforme sua relação com ela.

Portanto, considera-se a pretensão à correção material um terceiro elemento necessário ao conceito de direito. O status de sistema jurídico é adquirido quando o mesmo, além de considerar as categorias da legalidade conforme o ordenamento e a eficácia social, também erige uma pretensão corretiva. Entretanto, só pode-se sustentar que a pretensão a correção é um elemento necessário se também for possível sustentar que existe uma resposta moralmente correta extraível do sistema, pois, a irracionalidade da moral é um dos pressupostos de uma tese da separação. Assim, deve-se considerar se, e em que termos, é possível justificar uma convicção moral dentro de um contexto jurídico. É o que se verá a seguir.

\section{A possibilidade de justificação racional da moral e o discurso prático como atividade orientada por regras}

Considerando-se a proposta do capítulo anterior, no qual um dado sistema é qualificado como jurídico quando composto pela legalidade, eficácia e correção material, é mister avaliar se é possível de fato realizar uma fundamentação racional para o discurso moral. Se a resposta para essa questão for negativa, logo, deve-se retornar à tese de que a moral é irracional, portanto, deve-se abandonar o conceito acima trazido. Para tanto, novamente far-se-á uso da obra de Alexy, a fim de averiguar quais são os limites e as possibilidades de uma fundamentação do discurso moral.

Quando um sujeito busca, em uma dada discussão, argumentar sobre proposições normativas - juízos de dever e juízos de valor - onde transitam expressões como "bom" ou "devido", ele pode buscar um acordo através de duas maneiras: ou ele prova a verdade de sua proposição por meio da fundamentação, ou ele recorre a técnicas de persuasão (ALEXY, 2013). A segunda alternativa pode ser melhor explicada por ciências como a Psicologia. A 
primeira, entretanto, reflete o problema central a ser enfrentado aqui, que é saber se convicções morais são racionalmente fundamentáveis.

Teorias metaéticas como o Naturalismo e o Intuicionismo responderam a esse problema positivamente, delegando a linguagem moral uma função descritiva, ora reduzindo os enunciados normativos aos procedimentos das ciências de caráter empírico, como quis o Naturalismo, ora designando objetos e relações não empíricas, como quis o Intuicionismo. Entretanto, ambos foram altamente criticados, tanto pela impossibilidade de se descrever o que é "bom", tanto pelo fato de que, ao se dizer que os juízos de valor e de dever podem ser cognoscíveis por meio de uma faculdade humana não empírica, a ausência de critérios de avaliação levou o Intuicionismo ao limbo do subjetivismo ético (ALEXY, 2013).

A possibilidade de uma fundamentação racional de convicções morais exige a existência de formas e regras que permitam a diferenciação entre fundamentações válidas e inválidas das proposições normativas, o que não fizeram o Naturalismo e o Intuicionismo. Em outras palavras, é necessário haver um critério para saber quando se está diante de uma proposição normativa válida ou inválida, para não se cair no campo da irracionalidade. A análise da linguagem moral em Hare, amparada por conceitos da teoria dos atos de fala de Austin, contribuiu com essa tarefa com a elaboração de duas regras básicas de argumentação moral, o princípio da universalidade e o princípio da prescritividade, mais tarde readequados na teoria da argumentação de Alexy (2013).

Quando Hare fala em universalidade, parte de expressões descritivas que, partilhadas, compõe elementos valorativos. Assim, para o autor, quando se designa um objeto A como "bom", faz-se isso porque ele possui um conjunto de características que compõe o conjunto descritivo que se aplica no uso de "bom" no caso de A. Em proposições como "A é vermelho", existe a obrigação de se atribuir a todos os objetos de características relevantemente semelhantes a A o predicado vermelho (Alexy, 2013).

O mesmo ocorre com os juízos de dever. Alexy (2013) entende que para Hare, quando um sujeito diz a outro o que deve fazer, ele está de igual forma obrigando-se a ter a mesma atitude caso estivesse na situação inversa. Assim, se A deve a B, que por sua vez deve a C, havendo a possibilidade de se ordenar a prisão do devedor inadimplente, B deveria avaliar a proposição normativa que levaria $\mathrm{A}$ à prisão, pois, aceitando-a, também deveria aceitar a possibilidade de também ser preso, já que é devedor de C.

Embora os preceitos de Hare sozinhos sejam insuficientes para determinar as condições racionais do discurso, não por isso deixam de ser válidos, pois trazem consigo a 
ideia de que todos os potenciais participantes devem ter direito a uma igual consideração. Ainda, por meio deles pode-se inferir o papel do discurso moral como atividade que tem como função o equilíbrio racional de múltiplas pretensões.

A possível justificação racional da moral exige critérios mais complexos, que também envolvam argumentos e suas formas. Assim, deve-se ter em mente que, quem expressa um juízo moral implicitamente pressupõe uma regra que o sustente. Veja-se: a proposição normativa "A agiu mal" pode ser justificada pela proposição de fato "A mentiu". Entretanto, a passagem da razão de fato para a proposição normativa implica uma regra que diga que o fato ocorrido é uma razão para a proposição anunciada. Nesse caso, a proposição fática "A mentiu" pode justificar a proposição "A agiu mal" considerando-se a regra "mentir é moralmente reprovável”. Assim, pode-se afirmar que uma proposição normativa $(\mathrm{N})$ pode ser justificada por meio de uma razão fática $(\mathrm{G})$, por meio de uma regra $(\mathrm{R})$.

Pode-se igualmente dizer que, da mesma maneira que $(\mathrm{N})$ é justificada por meio de $(R)$ e $(G)$, alguém poderia questionar a validade de (R) como proposição normativa. Assim, surge a possibilidade (ou o dever) de fundamentar (R) por meio de uma razão e de uma regra de segundo nível, e assim sucessivamente, na medida em que forem postas em dúvida as fundamentações das proposições normativas. Por exemplo, poder-se-ia fundamentar a regra "mentir é moralmente reprovável” com uma razão de segundo nível (G) “mentir gera sofrimentos evitáveis", sustentada pela regra (R) de segundo nível "o que causa sofrimentos evitáveis é ruim" (ALEXY, 2013).

Esse efeito de fundamentações em cadeia que leva ao regresso ao infinito só pode ser evitado com uma decisão que já não precise ser fundamentada. Contudo, para tanto, ou se chegaria a uma decisão arbitrária ou, na melhor das hipóteses, em uma decisão explicável somente nos contextos da psicologia. No caso do problema exposto no início deste capítulo, poder-se-ia falar que, ou o sujeito justifica infindamente cada proposição normativa quando lhe é impelido a fazê-lo, ou o consenso ao cabo adquirido seria explicado unicamente pelas técnicas mentais de persuasão aplicadas para que o interlocutor tenha agido conforme seu entendimento.

Não é necessário comentar que ambas as alternativas são indesejadas. Entretanto, a racionalidade não se torna comprometida se, no lugar de infinitas proposições, figuram condições mínimas para que haja um consenso fundado. Havendo meios para a formação e controle das proposições normativas, pode-se chegar a um momento em que não seja necessário apresentar fundamentações, embora ainda seja possível. A tarefa de Alexy, 
partindo dessa proposta, foi, amparado pelas contribuições científicas que o antecederam, sistematizar o que chamou de "teoria geral do discurso prático racional". Portanto, a racionalidade do discurso, se possível, depende do cumprimento de determinadas condições discursivas, atribuídas tanto às proposições quanto ao comportamento dos integrantes do discurso.

Habermas colaborou significativamente com o projeto de Alexy, como o mesmo reconheceu mais tarde em sua obra. Entre suas contribuições, destacam-se algumas das características formais do discurso, próprias de uma situação ideal de fala. Nela, as coações externas e aquelas intrínsecas ao discurso são neutralizadas de forma a evitar a ocorrência de um pseudoconsenso (ALEXY, 2013). As regras elaboradas por Habermas expõem as condições mínimas para que haja um acordo racional, incluindo a garantia de ampla participação discursiva, o que compreende a possibilidade de todos os participantes problematizar e fundamentar proposições normativas ou expressar seus sentimentos e opiniões (ALEXY, 2013).

Também de acordo com a situação ideal de fala, em todo discurso que visa a correção racional existe uma aspiração à universalidade, ainda que essa não possa ser materialmente alcançada. Quando um ator justifica determinada proposição normativa, ele precisa apresentála de tal maneira que a torne aceitável por qualquer potencial integrante do discurso, inclusive a si mesmo, ainda que isso seja empiricamente inviável (ALEXY, 2013).

Alexy chamou de "regras fundamentais" o conjunto de condições normativas que possibilita uma comunicação linguística voltada para a correção (ALEXY, 2013). As regras fundamentais asseguram a coerência da comunicação entre os atores do discurso. Portanto, seu cumprimento mínimo deve ser observado para que haja uma real e efetiva comunicação, por um lado proibindo-se a contradição e o uso da mesma expressão com diferentes significados, por outro, exigindo-se a sinceridade e a universalidade nos atos de fala dos atores do discurso. Por conseguinte, nenhum sujeito pode justificar proposições que não aceita ou que não acredita, ou mesmo referir-se a diferentes objetos com a mesma expressão.

Ao lado das regras fundamentais, encontram-se as regras da razão, regras de carga de argumentação e as regras de transição. As regras de razão encontram respaldo nas condições discursivas já mencionadas, elaboradas por Habermas, referentes à igualdade de participação do discurso e da não-coerção. As regras de carga de argumentação referem-se, por sua vez, à distribuição do ônus argumentativo entre os atores do discurso. As regras de transição permitem a passagem entre as diversas espécies de discurso. 
Dito isso, parece viável afirmar que, apesar de haver diversas convicções axiológicas dentro de um único sistema populacional, as regras do discurso, apesar de não determinarem as convicções de que partem os atores, permitem a identificação de uma moral correta em termos discursivos. Contudo, não se irá negar que a teoria discursiva possui defeitos, ainda que não discutidos. Destaca-se, entretanto, que, observando-se o procedimento discursivo, mostra-se dificultoso crer que sujeitos racionais possam acordar livremente com o extermínio de uma parcela da população com base em crenças discriminatórias.

Assim, uma teoria argumentativa não trata de uma moral qualquer, ou de sua valoração perante outras, mas de uma moral que se torna correta por ser racionalizável por meio do discurso. Sem as condições discursivas, seria inviável determinar se uma dada proposição normativa é ou não justificável, o que é essencial em termos de direito. Se qualquer proposição normativa não fosse passível de justificação racional, então, de fato, o direito teria que ser segregado de qualquer conteúdo valorativo, para não correr o risco de se ver a injustiça aplicada em seu nome e em seu lugar.

No entanto, é importante destacar um limite intransponível do discurso. Em seus estudos, Hare (apud Alexy, 2013) distinguiu dois tipos de argumentação moral, uma na qual os sujeitos perseguem seus interesses, obrigando-se a considerar os interesses alheios tais quais os seus; e, outra, na qual os sujeitos perseguem seus ideais, ou seja, aquilo que tomam como "bom". Apesar de criticada, a distinção de Hare é útil. Quando um sujeito, disposto a impor seus ideais ao custo do sacrifício de seus próprios interesses e dos outros, como o nazista que considera correta sua morte caso fosse judeu, a argumentação moral torna-se inútil, ou ao menos isenta de eficácia. Hare chamou um sujeito assim de fanático. E o discurso, com suas regras de ampla participação, igualdade e universalidade, jamais produz efeitos quando não se está disposto a modificar-se segundo o regime do melhor argumento.

\section{A necessidade da racionalidade discursiva na identificação de condutas humanas contrárias à ética do serviço público}

Por que o servidor judeu não é punido por suas práticas religiosas? Ou mesmo, por que práticas racistas não são toleradas no âmbito da Administração Pública? Um jurista minimamente conhecedor dos mandamentos legais do sistema poderia responder a estas questões com base em algo como a Constituição Federal ou o Código de Ética dos Servidores Públicos. O Decreto ${ }^{\circ}{ }^{1} 1.171 / 94$, que instituiu o referido diploma, assim dispõe: 
XIV - São deveres fundamentais do servidor público:

$[\ldots]$

g) ser cortês, ter urbanidade, disponibilidade e atenção, respeitando a capacidade e as limitações individuais de todos os usuários do serviço público, sem qualquer espécie de preconceito ou distinção de raça, sexo, nacionalidade, cor, idade, religião, cunho político e posição social, abstendo-se, dessa forma, de causar-lhes dano moral;

Entretanto, com base no que foi exposto anteriormente, há razões para crer que, mais do que razões legais, como as normas garantidoras da liberdade de religião e da proibição à discriminação, existem razões morais para punir um servidor caso seja racista ou para não afastá-lo por ser judeu. Isso implica crer que, apesar de existirem sujeitos que, por suas convicções, discriminam negros ou judeus por haver, em seu entendimento, razões morais para tanto, o direito não está vinculado a uma moral qualquer, mas a uma moral correta. A diferença entre ambas, conforme abordado no capítulo anterior, reside elementarmente no fato de que, uma moral correta está necessariamente vinculada a uma pretensão à fundamentabilidade e à correção. Logo, é racionalmente justificável uma norma que proíba o racismo, principalmente tratando-se de uma repartição pública, mas dificilmente se poderá justificar uma norma que exclua dos quadros da Administração um sujeito devido à sua prática religiosa. Entretanto, é mais difícil identificar as variáveis deontológicas quando se está diante de uma norma possuidora de conceitos indeterminados:

XV - E vedado ao servidor público;

o) dar o seu concurso a qualquer instituição que atente contra a moral, a honestidade ou a dignidade da pessoa humana; (BRASIL, 1994)

Apesar das especificidades do Código de Ética, a resposta para a violação de um mandamento como o exposto acima depende da reconstrução dos conceitos de moralidade, honestidade e dignidade da pessoa humana. Além disso, é necessário realizar uma valoração sobre as ações cometidas pelo servidor para se poder reconhecer se houve ou não uma violação aos institutos normativamente protegidos. Este processo não pode ser concretizado com as ferramentas da lógica formal, mas produzido em um processo discursivo, tal qual exposto no capítulo anterior.

Por conseguinte, quando o servidor comete uma conduta ilícita, o Poder Público preenche o conteúdo de conceitos como "conduta ilibada" ou "moralidade". Nesses processos, 
os recursos do discurso jurídico, como a lei, os precedentes e a dogmática são parte dominante da argumentação, entretanto, são elementos insuficientes para a formação de um consenso sobre a tipificação e a punição do ato praticado. Assim, a argumentação prática assume um papel essencial para a formação de uma decisão mais correta, estando em consonância com as formas da argumentação jurídica.

A importância da argumentação é ainda maior quando se admite que o servidor público carrega o ônus de ter sua vida privada objeto passível de sindicância administrativa. Por conseguinte, mesmo aqueles atos que praticados fora da repartição ou fora das atividades regulares do serviço público podem ensejar a abertura de processo administrativo disciplinar e a aplicação de medidas sancionatórias. Assim compõe o Código de Ética do Servidor Público:

VI - A função pública deve ser tida como exercício profissional e, portanto, se integra na vida particular de cada servidor público. Assim, os fatos e atos verificados na conduta do dia-a-dia em sua vida privada poderão acrescer ou diminuir o seu bom conceito na vida funcional (BRASIL, 1994).

Ao ingressar no serviço público, o indivíduo passa a representar na figura de sua pessoa a honra e o crédito da Administração. Portanto, todo aviltamento atribuído ao servidor se reflete direta ou indiretamente na imagem que a sociedade possui do Poder Público. Uma vez instituídos os princípios orientadores da Administração Pública, a qual é presentada pelos servidores, a conduta dos mesmos deve ser estimada sempre em favor da honestidade, da probidade, da moralidade e do bem comum. Tratando-se do discurso jurídico, as convicções dos servidores já estão pré-estabelecidas em textos como a Constituição Federal. Portanto, não há espaço para atos praticados com pretensões de satisfação pessoal ou prejuízo alheio.

O Tribunal de Justiça do Rio Grande do Sul confirmou sentença condenatória, em sede de Ação Civil Pública, de servidor público municipal que cobrou valores indevidos para a realização de procedimentos parturientes em gestantes atendidas pelo SUS (BRASIL, 2014). O médico já havia sido condenado em primeiro grau pelo incurso no artigo $9^{\circ}$ da Lei de Improbidade Administrativa. Excluindo-se a análise quanto ao enriquecimento ilícito previsto no art. $9^{\circ}$, o qual demanda análise probatória acerca do pagamento efetuado pelas vítimas do servidor, deve-se atentar para o disposto no art. 11 da Lei 8.429/92, tipificado na conduta do servidor $^{5}$, apesar de absorvido pelo tipo do art. $9^{\circ}$ :

\footnotetext{
5 No caso em tela, o Tribunal reconheceu a violação ao disposto no artigo 11 da Lei de Improbidade Administrativa. Entretanto, pela técnica jurídica, o tipo descrito no artigo 11 é considerado subsidiário aos tipos
} 
Art. 11. Constitui ato de improbidade administrativa que atenta contra os princípios da administração pública qualquer ação ou omissão que viole os deveres de honestidade, imparcialidade, legalidade, e lealdade às instituições, e notadamente:

$[\ldots]$

Diversas gestantes foram impelidas a realizar pagamentos de diferentes valores, variáveis em cada caso, mesmo sendo atendidas pelo SUS, para então serem realizados os partos. Na fundamentação exposta pelo relator, além da condenação pelo enriquecimento ilícito, o servidor também foi enquadrado pela violação aos princípios da Administração Pública. Por que a atitude do servidor é moralmente condenável? Ou mesmo, esta condenação moral com efeitos jurídicos é fruto de um discurso pautado minimamente por condições racionais? Para se tentar chegar a uma resposta, faz-se necessário voltar aos mandamentos da argumentação prática expostos no capítulo anterior.

A conclusão do Tribunal de Justiça, a qual aqui se partilha, é que o comportamento do médico é valorativamente negativo, ou seja, que o mesmo agiu mal. A proposição normativa afirmada, conforme exposto no acórdão, é amparada pela razão fática de que o mesmo aproveitou-se de um momento único da condição humana, além da fragilidade intelectual, financeira e emocional de suas vítimas para impor uma cobrança juridicamente indevida.

\begin{abstract}
Como se depreende, eminentes Colegas, a prova testemunhal não deixa dúvida do agir doloso, intencional, injustificável, do réu Luis Carlos Michel, o qual aproveitava-se não apenas da condição de hipossuficiência econômica, mas mesmo social das pacientes, mas, sobretudo, e o que é ainda mais grave, de sua vulnerabilidade emocional, face ao delicado momento pela qual passa a gestante, que é justamente a ora do nascimento do bebê que carrega no ventre. Chega a ser desumano no agir do demandado quando afirma à paciente que seu filho não poderá nascer de parto natural, comumente chamado de parto normal, mas ao mesmo tempo cobra quantia em dinheiro para realizar a cesariana (BRASIL, 2014).
\end{abstract}

A conclusão presente na proposição normativa "o servidor agiu mau" depende da aceitação de uma regra que diga que tirar proveito próprio em cima da miséria alheia é ruim. Assim, pergunta-se se uma regra como essa possui condições de ser potencialmente universalizável. Ao que indica, sim. Nenhum sujeito em pleno gozo de suas faculdades mentais irá aceitar ser reduzido em sua existência em prol de pretensões egoístas de seu

descritos nos artigo $9^{\circ}$ e 10 . Assim expos o relator: "Portanto, uma vez presente quaisquer das condutas tipificadas nos artigos $9^{\circ}$ ou $10^{\circ}$, não se poderá cumular estas condutas com o art. 11, ficando a conduta descrita neste último, no sentido de violar princípios que regem a Administração Pública, absorvida pela tipificação descrita nos demais dispositivos de lei $-9^{\circ}$ ou $10^{\circ}$ ' (BRASIL, 2014). 
semelhante. Mesmo questionando-se a regra exposta, poder-se-ia justificá-la com a razão de fato de que pretensões egoístas causam sofrimento em massa, combinada com uma regra de segundo nível que diga que o que causa sofrimento em massa é ruim.

Portanto, considerando-se que mesmo não mencionadas na decisão, a conclusão atingida carrega consigo as convicções que justificam a validade de uma condenação moral do servidor público, mesmo porque as premissas morais de sustentação não foram problematizadas. Ainda, considerando-se que não houve entraves comunicacionais relativos a linguagem de transmissão, ou mesmo que o contraditório e a ampla defesa foram respeitados, a fim de possibilitar a carga argumentativa e a igualdade de problematização, não parece haver prejuízo exaltante a ponto de comprometer a racionalidade da decisão.

De fato, uma vez que o foco da defesa do servidor foi descaracterizar o enriquecimento ilícito, a maior preocupação dela foi destituir de crédito o conjunto probatório que sustentava as razões fáticas. Com isso, o servidor chamava a atenção para uma vida de dedicação ao bem humanitário, próprio da medicina, com dedicação à saúde da comunidade. Entretanto, um agir prático não substitui outro. Se as próprias vítimas se diziam agradecidas pelos serviços do médico, ainda que tenham pago por um serviço gratuito, isso somente revela o quão viciado foi o agir do servidor, que fez uso de coerção totalmente incompatível com o direito.

\footnotetext{
Em sendo assim, não me comovem os depoimentos prestados por testemunhas pelo demandado arroladas, dando conta de sua conduta ilibada, exercício humanitário da medicina, e etc. Independentemente de que o réu possa, como regra geral, ter pautado sua vida dentro dos mais elevados padrões de moralidade e honestidade, os fatos que ora estão sendo julgado são graves e devem ser punidos, ainda que esse possa ter sido um comportamento não habitual, muito embora os nove fatos narrados, o que pode significar, ainda, que muitos outros possam existir, semelhantes a estes, mas que apenas não vieram à tona. $\mathrm{E}$, se não existirem outros, $\mathrm{o}$ fato é que os que aqui estão em julgamento, reitero, são gravíssimos: legal e moralmente (BRASIL, 2014).
}

Assim, apesar de que, pela própria condição contra factual da situação ideal de fala, que não permite ser verificável empiricamente, a argumentação apresentada pelo Tribunal de Justiça se mostrou coerente, oportunizando a participação ao máximo possível no processo de decisão. $\mathrm{O}$ enquadramento do servidor em dispositivo que coíbe a violação aos princípios fundamentais da Administração exige que se avalie a conduta do servidor, e tal avaliação só pode ser produzida racionalmente com instrumentos da argumentação prática. Assim, mesmo que haja vítimas que aceitem a cobrança como moralmente correta, o direito aceita apenas 
como normativa uma moral racionalizável, o que parece condizente com a conclusão do Tribunal.

É evidente que, em uma multiplicidade de casos haverá alguns de amplo consenso sobre a valoração do agir prático do indivíduo, enquanto outros serão pautados por diversas discussões em que buscam fundamentar razões de diversos níveis. Isso ocorre também pelo amplo grau de abertura do discurso, o que o torna inservível para definir respostas únicas e corretas. Entretanto, considerando-se que o serviço público está pautado por inúmeros mandamentos de ordem axiológica, a racionalidade discursiva mostra-se um instrumento não só garantidor dos direitos fundamentais do servidor, mas também como um aparelho aliado da ordem democrática.

\section{Considerações finais}

O direito e a moral são faces de uma discussão que remonta o saber científico e filosófico da humanidade. O momento e as necessidades históricas moldaram a compreensão que os povos têm sobre o que o direito é e o que se espera dele. Hoje, a caminhada do constitucionalismo contemporâneo exige pensar um direito que seja minimamente vinculado a moral, haja vista a preocupação de sempre se decidir e aplicar o melhor direito aos jurisdicionados, concretizando os ideais esperados em um Estado Democrático de Direito.

A adoção de premissas de argumentação moral, e ainda, a própria percepção da inafastabilidade de sua presença, haja vista que a moral compartilha uma linguagem comum com o direito, por sua vez exige a formação de uma teoria normativa que oriente os discursos e permita identificar fundamentações válidas e inválidas. Muitas teorias da ética analítica buscaram desenvolver explicações para a fundamentação de convicções morais, associandose, alguns autores, aos princípios da teoria dos atos de fala e dos jogos de linguagem de Austin e Wittgenstein. Mais tarde, Habermas, integrante da Escola de Frankfurt, trouxe conceitos como a situação ideal de fala e seus princípios discursivos, contribuindo significativamente para a teoria do discurso prático racional geral, sistematizada por Alexy, considerada pelo autor um código da razão prática.

Com isso, observa-se que a ética do serviço público não é pautada somente pelas ideias de bem comum, mas como de diversos derivados morais: honestidade, solidariedade, igualdade, etc. Apesar de existirem normas voltadas a ações concretas, como roubo, por exemplo, em boa parte do tempo precisa-se de métodos para auferir que ações práticas 
contrariam os princípios tutelados pelo Poder Público. Assim, as regras da argumentação prática não são apenas necessárias para a identificação de uma moral correta em termos de direito, mas também essenciais para a produção de melhores decisões para o desenvolvimento do Estado, para a proteção do servidor e para a segurança da sociedade.

\section{Referências}

ALEXY, Robert. Conceito e validade do direito. Tradução de Gercélia Batista de Oliveira Mendes. 1. ed. São Paulo: Martins Fontes, 2009.

ALEXY, Robert. Teoria da argumentação jurídica: a Teoria do Discurso Racional como Teoria da Fundamentação Jurídica. Tradução de Zilda Hutchinson Schild Silva. Rio de Janeiro: Forense, 3. ed., 2013.

BRASIL. Decreto n. 1.171, de 22 de junho de 1994. Aprova o Código de Ética Profissional do Servidor Público Civil do Poder Executivo Federal. Diário Oficial da União, Brasília, DF, 23 de jun. 1994. Disponível em: < http://www.planalto.gov.br/ccivil_03/decreto/d1171.htm>. Acesso em: 10/01/2015.

BRASIL. Decreto-lei n. 4.657, de 04 de setembro de 1942. Lei de Introdução às normas do Direito Brasileiro. Diário Oficial da União, Rio de Janeiro, RJ, 09 de set. 1942. Disponível em: < http://www.planalto.gov.br/ccivil_03/decreto-lei/Del4657compilado.htm>. Acesso em: $10 / 01 / 2015$.

BRASIL. Lei 10.406, de 10 de janeiro de 2002. Institui o Código Civil. Diário Oficial da União, Brasília, DF, 11 de jan. 2002. Disponível em:

<http://www.planalto.gov.br/ccivil_03/leis/2002/110406.htm>. Acesso em: 23/02/2015.

BRASIL Tribunal de Justiça do Estado do Rio Grande do Sul. Apelação cível n ${ }^{\circ}$ 70062010632. Relator: Carlos Roberto Lofego Canibal. Data de julgamento: 17/12/2014. Data de publicação: [n.c.]. Disponível em:

$<$ http://www1.tjrs.jus.br/site_php/consulta/download/exibe_documento_att.php?ano=2014\&c odigo $=2129152>$. Acesso em: 09/02/2015.

CONTROLADORIA-GERAL DA UNIÃO. Relatório de acompanhamento das punições expulsivas aplicadas a estatutários no âmbito da administração pública federal. [S.l.: s.n.], 2015. Disponível em: <http://www.cgu.gov.br/assuntos/atividade-disciplinar/relatorios-depunicoes-expulsivas/arquivos/punicoes-2014-estatutarios-rev.pdf>. Acesso em 05/02/2014.

DWORKIN, R. M. Levando os direitos a sério. 1. ed. São Paulo: Martins Fontes, 2002.

KELSEN, Hans. Teoria pura do direito. Tradução de J. Cretella Jr. e Agnes Cretella. 9. ed. São Paulo: Revista dos Tribunais, 2013.

PACHUKANIS, E. B. Teoria geral do Direito e Marxismo. Tradução de Silvio Donizete Chagas. 1. ed. São Paulo: Acadêmica, 1988. 


\section{Sobre os autores:}

Luiz Egon Richter é Doutorando em Direito. Mestre em Desenvolvimento Regional. Especialista em Direito Constitucional pela UNISC e Especialista em Direito das Coisas pela Unisinos. Professor da graduação da Universidade de Santa Cruz do Sul, titular da disciplina de Direito Administrativo. Registrador Público. Endereço eletrônico: luizr@unisc.br

Augusto Carlos de Menezes Beber é Acadêmico do Curso de Direito da Universidade de Santa Cruz do Sul. Integrante do grupo de pesquisa "Teorias do Direito", coordenado pela Prof. a Dra. Caroline Muller Bitencourt, e do grupo de pesquisa "Patologias corruptivas nas relações entre Estado, Administração Pública e Sociedade: causas, consequências e tratamentos", coordenado pelo Prof. Dr. Rogério Gesta Leal. Integrante do projeto de pesquisa "O controle social e administrativo de políticas públicas: da teoria aos mecanismos de controle da função pública", coordenado pela Prof. a Dra. Caroline Muller Bitencourt. Bolsista do Programa UNISC de Iniciação Científica (PUIC). Endereço eletrônico: augusto_beber@yahoo.com.br 